\title{
A monumentalização do discurso na arqueologia do saber, de Michel Foucault
}

\author{
The monumentalization of discourse in the archaeology \\ of knowledge, by Michel Foucault
}

\section{La monumentalización del discurso en la arqueología del saber, de Michel Foucault}

\author{
iD) Ana Carolina Neves Dias \\ Universidade Federal de Juiz de Fora (UFJF), Juiz de Fora, Minas Gerais, Brasil. \\ E-mail: carolina.dias2807@outlook.com. \\ iD) Ana Paula El-Jaick \\ Universidade Federal de Juiz de Fora (UFJF), Juiz de Fora, Minas Gerais, Brasil. \\ E-mail: anapaulaeljaick@gmail.com.
}

Resumo: Este trabalho objetiva apresentar, sob a perspectiva da Historiografia da Linguística, algumas ideias na Arqueologia do Saber, em que Michel Foucault consubstancia o método arqueológico. Após caracterizar-se o clima de opinião em que o livro é publicado, destacase a transformação do documento em monumento como fundamental à análise discursiva foucaultiana. Além disso, descreve-se como as noções singulares de discurso e de enunciado apresentadas por Foucault ratificam tal análise como intrínseca ao discurso. Finalmente, propõe-se a integração da ideia foucaultiana de monumento aos estudos discursivos.

Palavras-chave: Historiografia da Linguística. Arqueologia do saber. História Descontínua. Monumento.

Abstract: This paper aims to present, under the perspective of the Linguistics Historiography, some ideas in the Archeology of Knowledge, in which Michel Foucault substantiates the archaeological method. After 
characterizing the climate of opinion in which the book is published, the transformation of the document into a monument stands out as fundamental for Foucault's discursive analysis. In addition, it describes how the singular notions of discourse and statement presented by Foucault ratify such an analysis as intrinsic to the discourse. Finally, it is proposed to integrate the foucauldian idea of a monument to discursive studies.

Keywords: Historiography of Linguistics. Archeology of knowledge. Discontinuous History. Monument.

Resumen: Este trabajo tiene el objetivo de presentar, basado en la perspectiva de la Historiografía Linguística, algunas ideas de la Arqueología del Saber, en la cual Michel Foucault sintetiza el método arqueológico. Después de caracterizar el clima de opinión en el cual el libro fue publicado, destaca la transformación del documento en monumento como fundamental para el análisis discursivo de Foucault. Además, describe como las nociones singulares de discurso y declaración presentadas por Foucault ratifican tal análisis como intrínseco al discurso. Al final, propone la integración de la idea de Foucault sobre monumento en los estudios discursivos.

Palabras claves: Historiografía Linguística. Arqueología del saber. Historia discontinua. Monumento.

Submetido em 09 de novembro de 2020.

Aceito em 02 de junho de 2021.

Publicado em 20 de outubro de 2021. 


\section{Considerações iniciais}

Este artigo é o resultado de uma pesquisa de Iniciação Científica norteada pelos pressupostos teóricos e metodológicos da Historiografia da Linguística, área situada no limiar entre linguística, história, filosofia e sociologia das ciências. No âmbito desse projeto, enseja-se a realização de estudos que retomem elos perdidos entre a filosofia, a literatura e os estudos linguísticos, uma vez que, habituados com os contornos disciplinares da academia, tais domínios são compreendidos isoladamente, não obstante terem sido, em outro momento histórico, intimamente relacionados.

A orientação transdisciplinar tem ganhado espaço nas ciências humanas desde que o próprio conceito de disciplina passou a receber críticas, como a de servir à manutenção de poderes estabelecidos. Um dos seus críticos é Michel Foucault, para quem "é provável que não se possa explicar seu papel [das disciplinas] positivo e multiplicador, se não se levar em consideração sua função restritiva e coercitiva" (FOUCAULT, 1970, p. 30). Nesse sentido, as disciplinas se determinam não apenas pelos temas de que tratam, mas também pela exclusão de determinados discursos se não responderem a determinadas exigências para caracterizarem-se como verdadeiramente científicos. Muitas vezes tais critérios consistem em questões puramente formais e advêm de concepções atomísticas acerca da categoria "objeto de análise", ou seja, para se ter um tema de pesquisa de uma "ciência digna desse nome", teríamos de delimitar um objeto isolável em padrões positivistas de separação (cirúrgica) entre observador e observado. No caso das ciências humanas, se levadas a sério, essas exigências seriam problemas consideráveis, dadas a multidimensionalidade e a transversalidade inerentes às questões humanas.

No caso dos estudos da linguagem, um possível efeito do enfoque disciplinar de uma ciência estritamente linguística é a centralidade dada à microlinguística, considerando-se que esse tipo de análise é entendido como "ciência hard", enquanto corren- 
A monumentalização do discurso na arqueologia do saber, de Michel Foucault Ana Carolina Neves Dias • Ana Paula El-Jaick

tes teóricas que tomam elementos extralinguísticos em suas análises - como o fazem aquelas sobre o nível discursivo - recebem o rótulo de ciências soft. É neste segundo grupo que nos colocamos a analisar um trabalho que fornece ferramentas conceituais para analisar o plano discursivo - sem nos sentirmos em um lugar menor. O não pertencimento à linguística hard é menos uma inferioridade do campo do que uma exigência do seu próprio objeto.

A Historiografia da Linguística demonstra consciência acerca dessa relação da ciência com jogos de poder ao não se restringir ao estudo de documentos inscritos no campo da Linguística enquanto disciplina. Assim, conforme Ronaldo de Oliveira Batista (2013), esse campo do saber pode eleger como objeto de estudo ideias constituídas no âmbito de diversos pensamentos sobre a linguagem, independentemente de figurarem em disciplinas ditas científicas ${ }^{1}$.

Assim, este texto emerge de um estudo de natureza bibliográfica, cujo corpus consiste em uma obra fundamental tanto para a filosofia quanto para a análise do discurso: a Arqueologia do Saber, na qual o filósofo Michel Foucault desenvolve a chamada fase arqueológica de seu pensamento, dedicada ao estudo da constituição de algumas ciências humanas. Uma vez que o termo arqueologia é tomado de empréstimo de Nietzsche por Foucault para designar seu método de análise das formações discursivas, interessa-nos apresentar a relação entre o papel da arqueologia na história propriamente dita diante da análise discursiva, tal como concebida pelo filósofo francês. Nessa tarefa, ganham centralidade as ideias de monumento e de acontecimento discursivo. Reside na reflexão proposta sobre o conceito de monumento o diferencial de nosso trabalho, pois, apesar de ser frequentemente citado em textos exegéticos ${ }^{2}$, o termo não recebe tanto destaque como aqueles recebidos por noções como as de discurso, enunciado, formação discursiva.

\footnotetext{
1 Não obstante este trabalho se apresente como filiado à Historiografia da Linguística, concordamos com Cristina Altman, para quem as nomenclaturas História das Ideias Linguísticas e Historiografia da Linguística não designam propostas substancialmente diferentes. A este respeito, o próprio texto de Batista (2013) é elucidativo.

2 Cf.: DELEUZE (1987); MACHADO (1983); DREYFUS e RABINOW (1995); DOSSE (1991); VEIGA-NETO (2006); BARBOSA (2004).
} 
A monumentalização do discurso na arqueologia do saber, de Michel Foucault Ana Carolina Neves Dias • Ana Paula El-Jaick

Por conta da natureza conceitual e do caráter de iniciação à pesquisa dos quais este artigo é fruto, as noções serão apresentadas de modo estrito ao trabalho cujo título já mencionamos. Enfatizamos este limite para evitar antecipações quanto ao emprego dos termos monumento e acontecimento no conjunto dos escritos foucaultianos, isto é, em sua obra. Ao mesmo tempo, julgamos que tal decisão não é totalmente estranha aos princípios foucaultianos, pois, como assinala o próprio Foucault (1969), a noção de "obra" apaga as descontinuidades próprias à historicidade discursiva, fazendo com que o conjunto de textos ao qual se atribui determinada autoria pareça um todo homogêneo, o que não se dá ${ }^{3}$. Então, delimitamos nosso objeto de análise sabendo tanto de sua "insuficiência" quanto de sua problematização feita pelo próprio Foucault (que, aliás, coloca também em xeque o conceito de "autor" em seu trabalho arqueológico).

Quanto à metodologia da pesquisa, tomamos como direcionamento as preconizações de Pierre Swiggers, segundo quem o historiógrafo da linguística deve "partir de uma fase heurística, e avançar através de uma análise argumentativa e de uma síntese histórico comparativa, em direção a uma hermenêutica historicamente fundamentada" (SWIGGERS, 2010, p. 2). Mais precisamente, Swiggers (2013) divide a organização do trabalho na área da historiografia linguística em três fases: uma primeira fase heurística, que consiste na leitura dos textos-fonte e na catalogação das ideias; uma fase hermenêutica, em que se evoca o uso de categorias interpretativas, e, finalmente, a fase executiva, em que o estudo é divulgado através de trabalhos acadêmicos - fase de que faz parte este artigo.

Cumpre dizer, então, da organização do texto, ligada aos princípios desenvolvidos por Konrad Koerner (1995): ao princípio de contextualização, ao princípio de imanência e ao princípio de adequação. O princípio de contextualização diz respeito à recons-

3 Em Arqueologia do saber, Foucault questiona até mesmo o conceito de livro, que, por estabelecer relações com outros textos, não poderia ser considerado uma unidade completa. Conscientes dessa visão problematizadora, da qual não discordamos radicalmente, ainda assim tomamos como corpus a Arqueologia do Saber, um livro. De certo modo, entendemos que, embora remeta a textos anteriores, dialogue com outros que lhe são contemporâneos e enseje escritos futuros, um livro deve possuir algum princípio de coesão, porque, do contrário, a própria publicação da Arqueologia do Saber seria impossível. 
tituição do clima de opinião em que o documento linguístico se inscreve, evocando, para tanto, referências de outras disciplinas - no que Batista chama de "vocação interdisciplinar que define a Historiografia da Linguística como uma observação analítica sobre eventos dos estudos da linguagem situados historicamente" (BATISTA, 2013, p. 76). Conforme o princípio de imanência, por sua vez, deve haver uma abordagem mais textual do conteúdo do documento linguístico a ser analisado, o que não significa ignorar as dificuldades nessa abordagem imanente, posto que o próprio fazer da pesquisa implica o estabelecimento de gestos de leitura (no plural). Por fim, o princípio de adequação diz respeito à realização de análises a partir dos esforços interpretativos do pesquisador, que pode então estabelecer aproximações e avaliações críticas acerca da leitura realizada.

Destarte, embora as recomendações de Konrad Koerner sejam princípios para a pesquisa, e não para a escrita em si, é com base nesses direcionamentos que delimitamos a tessitura deste trabalho. Respondendo ao primeiro princípio, na próxima seção apresentaremos o clima de opinião em que a Arqueologia do Saber se inscreve, atendo-nos ao programa de investigação em que surge e às suas condições de possibilidade. Em seguida, apresentaremos mais diretamente as ideias de Foucault, em conformidade com o segundo princípio, intencionando abordar, através da materialidade de seu texto, pontos fulcrais para o entendimento de sua análise discursiva. Assim, contemplaremos: a noção de descontinuidade; a relação que esta, por sua vez, permite estabelecer entre as noções de monumento e de acontecimento discursivo, e, se bem que brevemente, a maneira como Foucault compreende o discurso e o enunciado. Ao final deste percurso, será possível mostrar, com base no ideário arqueológico, como a noção de discurso-monumento pode ser sustentada. Finalmente, fazemos considerações sobre a concepção de linguagem assumida no trabalho em questão, propondo a integração da ideia foucaultiana de monumento aos estudos discursivos. 


\section{Condições de emergência da Arqueologia do saber}

Para reconstituir o clima de opinião no qual a Arqueologia do Saber emerge, convém remontar aos meados do século $\mathrm{XX}$, que concentram uma efervescência de teorias e de quadros epistemológicos diversos nos estudos linguísticos ${ }^{4}$. Destaca-se, nesse período, três acontecimentos na área: a virada linguística, no que concerne à filosofia da linguagem, a virada pragmática e a virada cognitivista, na linguística propriamente dita.

Como nos ensina Danilo Marcondes (1999), até o fim do século $\mathrm{XIX}$ as correntes do idealismo absoluto e do empirismo dominavam a filosofia anglo-saxã. Em alternativa a tais perspectivas, dá-se a virada linguística, caracterizada pela transferência das questões filosóficas para o campo da linguagem e do significado, entendendo que as respostas para essas perguntas serão dadas a partir de análises linguísticas. Destarte, ainda conforme Marcondes, a filosofia da linguagem analítica é um ponto fundamental dessa virada, tomando para si dois compromissos: analisar a estrutura lógica das sentenças e investigar problemas filosóficos através do estudo do funcionamento de conceitos centrais para tais problemas na linguagem comum. Esses dois objetivos dão origem, ainda segundo o autor, respectivamente, à filosofia da linguagem em seu sentido mais estrito (esse da "filosofia da linguagem analítica"), que mobiliza conceitos como de "verdade e falsidade", e à filosofia da linguagem ordinária, que analisa a própria linguagem comum, entendendo que não há uma linguagem lógica no "fundo", ou "por trás" da linguagem corrente. Nesse sentido, a virada pragmática se liga diretamente a esta segunda vertente da filosofia da linguagem, cujos expoentes mais emblemáticos são o segundo Ludwig Wittgenstein, notadamente com as Investigações Filosóficas (1953), e John Langshaw Austin, com Quando Dizer é Fazer (1962). Vamos

\footnotetext{
4 "Climate of opinion" é uma expressão de Koerner para tratar do que ele chamou de "princípio de contextualização" das teorias linguísticas. Sua premissa é a de que: "The first principle for the presentation of linguistic theories propounded in earlier (pre-twentieth-century) periods concerns the establishment of the general 'climate of opinion' of the period in question. Linguistic ideas have never developed independently of other intellectual currents of the time; what Goethe called the 'Geist der Zeiten' has always left its imprint on linguistic thinking. At times, the influence of the socio-economic and even political situation must be taken into account as well" (1995, p. 13).
} 
A monumentalização do discurso na arqueologia do saber, de Michel Foucault Ana Carolina Neves Dias • Ana Paula El-Jaick

nos demorar mais nesta vertente da filosofia da linguagem por ser aquela que nos interessa para examinarmos a arqueologia foucaultiana.

A tese principal das aforísticas Investigações Filosóficas é a de que o significado das sentenças linguísticas não é estabelecido em termos de sentido e de referência, mas sim a partir dos seus usos. Em uma passagem das Investigações, o estudioso ilustra sua concepção de linguagem com o exemplo de um suposto bilhete entregue a um feirante, no qual se lê "cinco maçãs vermelhas". O filósofo demonstra que o contato com esses signos desencadeia antes ações do vendedor do que reflexões sobre o significado de cada palavra. Nesse espírito, desenvolve-se a noção de jogos de linguagem, que designa o todo complexo formado pela linguagem e pelas atividades às quais se relaciona. Esses jogos se assemelham entre si, mas não se reduzem a uma essência única. Assim, segundo Marcondes, a concepção wittgensteiniana de linguagem prevê "regras pragmáticas $(\$ \S 54,82-88,567)$, de uso, constitutivas dos jogos, que tornam possíveis os atos que os jogadores realizam" (MARCONDES, 2010, p. 19).

Austin, em congruência com a visão pragmática ${ }^{5}$ apresentada por Wittgenstein, desenvolvia, desde os anos 1940, um método para a análise do significado considerando informações contextuais, como: quem fala, de que maneira, por quais razões e quando diz. Essa atitude filosófica compreende o significado linguístico como constituído no uso, dissolvendo, assim, "a separação radical entre 'linguagem' e 'mundo', porque o que consideramos a 'realidade' é constituído exatamente pela linguagem que adquirimos e empregamos" (MARCONDES, 1990, p. 10). Em sua teoria dos atos de fala, Austin entende a linguagem como meio de ação no real, e não como mera descrição deste. Isso explica o abandono do critério de verdade/falsidade das proposições em benefício da utilização de conceitos como o de "condições de felicidade" dos atos de fala, evocado para designar as razões do sucesso ou insucesso do falante.

5 Apesar de o próprio Wittgenstein não utilizar esse termo (o que é compreensível, dada sua formação como engenheiro aeronáutico), é reconhecida a influência que seu pensamento maduro exerceu para os estudos pragmáticos na Linguística. 
A monumentalização do discurso na arqueologia do saber, de Michel Foucault Ana Carolina Neves Dias • Ana Paula El-Jaick

A virada cognitivista, na linguística, tem como marco inicial a publicação de Syntatic Structures, em 1957, por Noam Chomsky. Nesse livro, o linguista apresenta as bases da teoria gerativa, entendendo a linguagem como uma faculdade cognitiva inata e específica em relação a outros conhecimentos humanos. Tal modelo teórico teve repercussão expressiva, levando o autor a publicar, na década seguinte, outros escritos caros à sua construção teórica e aos estudos linguísticos como um todo, como Current Issues in Linguistic Theory (1964), Aspects of the Theory of Sintax (1965), Cartesian Linguistics (1966), Barriers (1968) e The Sound of Pattern of English (1968).

Para muitos estudiosos, o gerativismo é recebido como "divisor de águas" nos estudos da linguagem, e isso se deve sobretudo às diferenças que estabelece em relação aos estruturalismos precedentes $^{6}$. As direções de pesquisa do "estruturalismo americano" rumaram, por um lado, a um relativismo linguístico - expresso na hipótese Sapir-Whorf, segundo a qual a linguagem determina o pensamento - e, por outro, a um behaviorismo - defendido por Leonard Bloomfield como explicação para a aquisição da linguagem por bebês. Chomsky, por seu turno, vai de encontro a essas perspectivas ao lançar-se em estudos com vistas à descrição de uma gramática universal inata, biológica, e a uma explicação para a criatividade linguística humana de gerar potencialmente infinitos novos proferimentos gramaticais de uma língua.

Contudo, a ideia de uma ruptura completa entre as perspectivas estruturalista e gerativista é questionável. Afinal, ao se ater à competência (capacidade mental de criar enunciados bem formados) em oposição ao desempenho (o que é efetivamente enunciado), teorizando a partir de um falante ouvinte ideal, o gerativismo dá continuidade ao formalismo na análise linguística. Permanece, então, uma visão despreocupada com o sujeito real, histórica e socialmente situado, que utiliza a linguagem.

\footnotetext{
6 A tradição entende haver um estruturalismo europeu, cuja publicação em 1916 do Curso de Linguística Geral de Ferdinand de Saussure é um marco. Além desse, haveria um estruturalismo americano, cuja principal figura é Leonard Bloomfield - aqui, a questão da aquisição da linguagem é fundamental, com empréstimo da psicologia behaviorista em sua formulação básica. Ainda neste artigo, veremos que uma das maiores críticas lançadas aos dois estruturalismos no chamado "pós-estruturalismo" concerne a um apagamento do sujeito - essa informação é importante para a discussão que faremos em seguida sobre a Arqueologia.
} 
A monumentalização do discurso na arqueologia do saber, de Michel Foucault Ana Carolina Neves Dias • Ana Paula El-Jaick

Além e por causa dessas duas "viradas" - o estudo pragmático do significado e o estudo da linguagem em sua instância cognitiva -, surgem em meados do século XX disciplinas com orientações interdisciplinares, entre as quais destacam-se a análise da conversação, a sociolinguística, a análise do discurso, a psicolinguística, a linguística de texto, e essa não é uma lista exaustiva?.

É em meio a essa pluralidade de teorias e disciplinas em emergência nos estudos da linguagem que Foucault publica a Arqueologia do Saber (1969), livro ao qual vamos nos dedicar mais diretamente nas seções subsequentes.

\section{História, Arqueologia e Crítica Documental}

O livro sobre o qual nos debruçamos é lançado por Foucault após outros três, intitulados História da Loucura na Idade Clássica (1961), Nascimento da Clínica (1963) e As palavras e as coisas (1966) e um ano antes do proferimento de $A$ ordem do discurso, aula considerada introdutória à sua chamada fase genealógica ${ }^{8}$. Situamos a Arqueologia do Saber nessa cronologia porque, ao longo do texto em questão, o autor faz diversas menções a trabalhos antecedentes, com o intuito de demonstrar quais procedimentos e categorias foram mobilizados em suas análises discursivas. Portanto, o livro em questão pode ser compreendido como uma síntese teórico-metodológica que consubstancia a arqueologia, ao mesmo tempo que resolve ambiguidades e delimita o estatuto de tal proposta frente a outras análises da linguagem e à história das ideias.

O professor francês introduz seu texto chamando a atenção para uma mudança nas análises históricas, mais precisamente

\footnotetext{
7 Estas "tendências hifenizadas", como são chamadas por estudiosos como L. A. Marcuschi, não somente estão em desenvolvimento, como também não nasceram, evidentemente, a partir de eventos isolados. Contudo, parece adequado precisar alguns acontecimentos históricos que podem introduzir o leitor a uma pesquisa posterior mais aprofundada. A Análise da Conversa assume como marco inaugural a publicação Studies in Ethnomethodology (1960), de Harold Garfinkel; a Sociolinguística tem seu início comumente situado em 1964, com a publicação de livros de Gumperz, Labov e uma conferência seminal de William Bright nos Estados Unidos. A Análise do Discurso Francesa destaca-se em 1969, com a publicação de Análise Automática do Discurso, por Michel Pechêux, e a própria Arqueologia do saber, de Foucault. A Psicolinguística, existente antes mesmo dos anos 1960, quando era disseminada por psicólogos como Charles Osgood, passa a aderir, após críticas de Chomsky, a algumas premissas do gerativismo.

8 A divisão entre arqueologia e genealogia é aqui reproduzida a partir de didatizações propostas por alguns comentadores de Foucault, não dele próprio. Para mais informações sobre isso, cf. MACHADO, 2008; DREYFUS e RABINOW, 1995.
} 
A monumentalização do discurso na arqueologia do saber, de Michel Foucault Ana Carolina Neves Dias • Ana Paula El-Jaick

para a ênfase na continuidade, pela história tradicional, dar lugar à ênfase na descontinuidade, pela dita história nova. Para o filósofo, a grande diferença entre essas duas formas de história encerra-se na crítica do documento:

Digamos, para resumir, que a história, em sua forma tradicional, se dispunha a "memorizar" os monumentos do passado, transformá-los em documentos e fazer falarem estes rastros que, por si mesmos, raramente são verbais, ou que dizem em silêncio coisa diversa do que dizem; em nossos dias, a história é o que transforma os documentos em monumentos e que desdobra, onde se decifravam rastros deixados pelos homens, onde se tentava reconhecer em profundidade o que tinham sido, uma massa de elementos que devem ser isolados, agrupados, tornados pertinentes, inter-relacionados, organizados em conjuntos. Havia um tempo em que a arqueologia, como disciplina dos monumentos mudos, dos rastros inertes, dos objetos sem contexto e das coisas deixadas pelo passado, se voltava para a história e só tomava sentido pelo restabelecimento de um discurso histórico; poderíamos dizer, jogando um pouco com as palavras, que a história, em nossos dias, se volta para a arqueologia - para a descrição intrínseca do monumento (FOUCAULT, 2008, p. 8).

Esta passagem merece especial atenção, pois o termo arqueologia, que nomeia a metodologia de Foucault, aparece associado a dois outros conceitos, monumento e documento, centrais para a defesa de que a ênfase na continuidade ou na descontinuidade serve a propósitos diferentes, como veremos adiante. Nesse sentido, a imagem da arqueologia, de caráter procedimental, ora documentaliza os monumentos, fazendo-os falar mais do que dizem por si, ora monumentaliza os documentos, desdobrando-os numa dimensão complexa, a partir da qual o historiador deve operar.

Atribuição semelhante àquela exercida na nova história parece desempenhar a arqueologia na análise do discurso proposta por Foucault. Se a arqueologia se volta para a "descrição intrínseca" do 
A monumentalização do discurso na arqueologia do saber, de Michel Foucault Ana Carolina Neves Dias • Ana Paula El-Jaick

monumento na nova história, analogamente, se volta para a descrição intrínseca do discurso na análise discursiva. Isto nos encaminha para a possibilidade de um discurso-monumento, posto que, em vez de interpretado em termos de não-ditos ou de gênese autoral, o discurso deve ser tratado em sua irrupção histórica e material. Como a ideia de um discurso-monumento não é explícita, advogar-se-á em seu favor a partir de excertos do texto em análise.

\section{A defesa da descontinuidade}

$\mathrm{Na}$ seção anterior, pontuamos que as análises históricas orientadas pela continuidade ou pela descontinuidade servem a propósitos distintos, segundo Foucault. A fim de elucidar em quais sentidos tais noções são utilizadas, remontamos a alguns aspectos da filosofia do conceito elaborada por Georges Canguilhem. Conforme ensina Roberto Machado (2008), o autor se interessa pelo estudo das ciências à medida que instauram e atualizam o pensamento racional. Uma vez que em sua perspectiva a ciência constrói a racionalidade, e não o contrário, o interesse de Canguilhem se volta para os conceitos, considerados por ele o mais substancial das ciências e, portanto, fundamentais para a análise da constituição dessa racionalidade. Por esse olhar direcionado ao seu objeto de estudo, sua perspectiva de análise distancia-se das histórias das ciências factuais, caracterizadas por privilegiarem cronologias.

Não obstante, o aspecto que interessa ao presente trabalho é o emprego de uma história descontínua com sentido anti-positivista. Canguilhem assinala que a ideia de progresso nas ciências é tradicionalmente identificada com um avanço linear em direção à verdade. Por esta ótica, quanto maior o recuo cronológico de uma teoria em dada ciência, mais distante ela estaria da verdade, ao passo que, quanto mais recente, mais próxima. Então, o autor vai de encontro a essa tese, postulando o progresso como descontínuo. Nesse sentido, os conceitos são analisados pelo professor em suas "filiações descontínuas", mesmo antes de se integrarem 
A monumentalização do discurso na arqueologia do saber, de Michel Foucault Ana Carolina Neves Dias • Ana Paula El-Jaick

à determinada ciência e, ainda, transgredindo os próprios limites estabelecidos entre as ciências.

Por esse ponto de vista que acabamos de sumarizar, ideias como a de "pré-ciência", bem como a de "precursor" reproduzem uma visão da história da ciência contada pela própria ciência: uma caminhada irreversível para a racionalidade, em que não se considera o valor de determinada teoria em sua irrupção histórica, mas a partir de um presente sempre superior ao passado. Em síntese, para Canguilhem, "compreender o que foi a instrução do momento é tão importante quanto expor as razões da destruição posterior" (CANGUILHEM apud MACHADO, 2008, p. 29).

Retomar brevemente o pensamento de Canguilhem - que foi inclusive o orientador de Foucault em seu doutorado - é útil porque, a partir de sua crítica à forma através da qual o progresso é pensado pelas ciências, podemos entender as implicações da descontinuidade presente tanto em sua filosofia do conceito como na história nova e na proposta arqueológica de Foucault 9 . A contribuição principal de Canguilhem é a percepção de que a linearidade do progresso é parcial e motivada, posto que, submetida à prova, a teleologia da razão não se confirma, dando-se o progresso descontinuamente. De modo análogo, Foucault percebe que a continuidade no discurso histórico tradicional - que demarca uma origem a partir da qual os acontecimentos se desdobram linear e dialeticamente - não é arbitrária. Para o autor, a história não se reduz a uma sucessão linear. Vejamos como se sustenta isso.

A partir da mudança epistemológica assinalada por Foucault no campo da história propriamente dita, o descontínuo, antes tratado como "lacuna indiferente entre duas figuras positivas" (FOUCAULT, 2008[1969], p. 10), investe-se de positividade, decorrendo disso várias implicações, como dificuldades no estabelecimento de corpus. Em suas palavras, "o problema não é mais a tradição e o rastro, mas o recorte e o limite; não é mais o fundamento que se perpetua, e sim as transformações que valem como fundação e

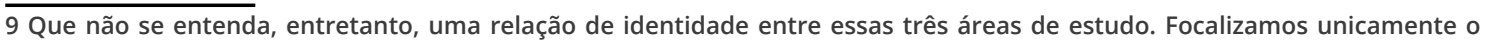
problema da descontinuidade que se apresenta, também com suas diferenças, nesses três terrenos. 
renovação dos fundamentos" (FOUCAULT, 2008[1969], p. 6, grifo nosso). Grifamos "problema" porque talvez seja possível afirmar que a descontinuidade não é evocada apenas no sentido de "questão", mas também como algo incômodo e insurgente a determinado modo de pensar. Mais precisamente, se aceitamos que "[f]azer da análise histórica o discurso do contínuo e fazer da consciência humana o sujeito originário de todo o devir e de toda prática são as duas faces de um mesmo sistema de pensamento" (FOUCAULT, 2008 [1969], p. 14), a descontinuidade é potencialmente perturbadora ao castelo epistemológico ocidental.

Para o professor do Collège de France, a "continuidade" não existe de forma imanente. Um indício que corrobora essa tese é a asserção de que, apesar de terem "função precisa", as noções que sustentam a continuidade "não têm uma estrutura conceitual bastante rigorosa" (FOUCAULT, 2008 [1969], p. 23). Isso leva a crer que elas são motivadas menos por análises pautadas nas regras de funcionamento efetivo dos discursos do que por interesses de um olhar positivista sobre a história.

Ainda conforme o filósofo, a história linear (não só a propriamente dita, mas as histórias ancoradas na continuidade) exclui um sem número de camadas de acontecimentos, procedendo de modo a suprimir as diferenças e a "encontrar sob ela [a diferença] uma diferença menor e, abaixo desta, uma outra ainda mais limitada, e assim indefinidamente até o limite ideal que seria a não-diferença da perfeita continuidade" (FOUCAULT, 2008 [1969], p. 192). Tal estratégia faz crer-nos nada assujeitados ao desenrolar histórico, mas sujeitos cuja consciência convive tranquila e naturalmente com os acontecimentos. Se o filósofo francês é enfático sobre o "desserviço" prestado pela continuidade, é para introduzir-nos à sua proposta epistêmica: uma descentralização do homem, através da positivação da descontinuidade.

Para essa positivação, pilares necessários à continuidade como as ideias de tradição, de influência, de origem, de obra e de livro são suspensas. Nas palavras do filósofo, a arqueologia, ao operar com a descontinuidade, deve ser capaz de 
A monumentalização do discurso na arqueologia do saber, de Michel Foucault Ana Carolina Neves Dias • Ana Paula El-Jaick

mostrar que elas [noções que ligam os discursos] não se justificam por si mesmas, que são sempre o efeito de uma construção cujas regras devem ser conhecidas e cujas justificativas devem ser controladas; definir em que condições e em vista de que análises algumas são legítimas; indicar as que, de qualquer forma, não podem mais ser admitidas (FOUCAULT, 2008 [1969], p. 28).

Para tanto, a arqueologia deve operar através de unidades e princípios específicos, pois só assim será possível verificar em que medida noções gerais como as apresentadas há pouco contemplam ou distorcem sua realidade. Foucault admite que sua análise descontínua não seria recebida sem resistências, pontuando que certas mentes "não podem admitir que se limpe a mudança de todos os modelos adventícios, que se tire dela, ao mesmo tempo, seu primado de lei universal e seu status de efeito geral, e que ela seja substituída pela análise das transformações diversas." (FOUCAULT, 2008 [1969], p. 194). Veja-se que conceber mudanças como efeitos gerais ou leis universais, como cortes sincrônicos em vez de pensar as diversas transformações como de distintas durações -, é uma forma de moldar a realidade para torná-la mais amigável à nossa compreensão. A partir dessa leitura, entende-se o tom provocativo de Foucault na passagem acima - e que se repete ao longo do texto - como meio de afirmar sua oposição ao sistema de pensamento que, amparado pela história que entende os acontecimentos históricos como uma linha contínua, sustenta um antropocentrismo baseado na racionalidade humana ${ }^{10}$.

Revelada a posição epistemológica da arqueologia, veremos que as unidades por ela utilizadas se alinham ao intuito de obter explicações diferentes daquelas nas quais o mundo nos aparece ordenado e pacífico. Vamos nos aprofundar em aspectos mais

\footnotetext{
10 É possível situar essas críticas à centralização da consciência humana (por Foucault) e ao progresso linear das ciências (por Canguilhem) a partir do que caracteriza o pós-moderno na concepção de Jean-François Lyotard: a incredulidade para com as metanarrativas. Esse termo designa as grandes narrativas às quais a ciência moderna recorre para provar seu estatuto de verdade. A necessidade de legitimação é o que justifica o apelo da ciência ao discurso filosófico moderno, que mobiliza noções como "a dialética do Espírito, a hermenêutica do sentido, a emancipação do sujeito racional ou trabalhador, o desenvolvimento da riqueza" (LYOTARD, 1989, p. 11). Não obstante, logo se vê que a ciência não se legitima "sem recorrer a outro saber, a narrativa, que é para ele o não saber, em cuja ausência ele é obrigado a pressupor-se a si mesmo, caindo assim no que condena, a petição de princípio, o preconceito" (LYOTARD, 1989, p. 64). Em outros termos, a ciência contradiz a si mesma na medida em que baseia sua legitimidade em outro tipo de narrativa, a filosofia que privilegia o sujeito fundante.
} 
A monumentalização do discurso na arqueologia do saber, de Michel Foucault Ana Carolina Neves Dias • Ana Paula El-Jaick

procedimentais a seguir, tendo em mente as noções de monumento e de acontecimento discursivo, intimamente ligadas à ideia de descontinuidade.

\section{O acontecimento discursivo e o monumento}

Como vimos, a análise arqueológica do discurso opõe-se à história contínua, desdobrando-se a partir da mutação epistemológica que prevê a descontinuidade como a forma através da qual deve ser entendida nossa história - e, também, o homem. Assim, ao introduzir os aspectos metodológicos de sua teoria, Foucault preconiza a apreensão dos discursos como uma "população de acontecimentos dispersos". Precisemos esta ideia com base nas seguintes palavras:

a supressão sistemática das unidades inteiramente aceitas permite, inicialmente, restituir ao enunciado sua singularidade de acontecimento e mostrar que a descontinuidade não é somente um desses grandes acidentes que produzem uma falha na geologia da história, mas já no simples fato do enunciado; faz-se, assim, com que ele surja em sua irrupção histórica; o que se tenta observar é essa incisão que ele constitui, essa irredutível - e muito frequentemente minúscula - emergência (FOUCAULT, 2008 [1969], p. 31).

A restituição da singularidade de acontecimento ao enunciado corresponde a uma positivação da descontinuidade, a qual deixa de ser rara e homogênea como a história linear fazia supor, para figurar na proliferação incessante - mas fini1ta - dos enunciados. A partir desse novo ponto de vista, relações diferentes daquelas previstas a partir das análises que partem de categorias limítrofes, como as de disciplina e de obra, poderão ser esboçadas no campo enunciativo. O filósofo prossegue em sua definição do enunciado, como 
um acontecimento que nem a língua nem o sentido podem esgotar inteiramente. Trata-se de um acontecimento estranho, por certo: inicialmente porque está ligado, de um lado, a um gesto de escrita ou à articulação de uma palavra, mas, por outro lado, abre para si mesmo uma existência remanescente no campo de uma memória, ou na materialidade dos manuscritos, dos livros e de qualquer forma de registro; em seguida, porque é único como todo acontecimento, mas está aberto à repetição, à transformação, à reativação; finalmente, porque está ligado não apenas a situações que o provocam, e a consequências por ele ocasionadas, mas, ao mesmo tempo, e segundo uma modalidade inteiramente diferente, a enunciados que o precedem e 0 seguem (FOUCAULT, 2008 [1969], p. 31).

A partir desse excerto é possível destacar que, se a língua e o sentido estão aquém de uma descrição do acontecimento discursivo, ao ocupar-se desta, a arqueologia se situa em um nível diferente de algumas análises da linguagem que lhe são contemporâneas, como a gramática gerativa e a filosofia da linguagem analítica. Afinal, por considerar "elementos significantes que foram traçados ou articulados - e, mais precisamente, a essa singularidade que as faz existirem" (FOUCAULT, 2008 [1969], p. 129), a proposta foucaultiana difere-se da gramática gerativa, que, preocupada com a "aceitabilidade" de enunciados possíveis, não demanda que estes sejam reais, e da filosofia da linguagem analítica, a qual, vinculada à lógica, conforme Auroux (1998), interessa-se pela verdade ou falsidade das proposições e encerra-se no nível de uma linguagem geral, formalizada.

Além disso, a passagem acima permite entender, ainda, que considerar o enunciado como acontecimento não é o mesmo que se aferrenhar à enunciação; afinal, esta não é repetível, ao passo que o enunciado, cuja singularidade é bastante específica, o é (nos deteremos nessa unidade logo adiante). Ademais, como sua existência implica acontecimentos discursivos que o precedem e o seguem, não pode ser descrito isoladamente. 
Neste ponto, precisamente, devemos retomar a noção de monumento, apresentada nas primeiras páginas da Arqueologia do saber e centralizada aqui como a chave de leitura segundo a qual se pode conceber em Foucault um discurso-monumento. A ideia central é de que a transformação do documento em monumento, isto é, em "uma massa de elementos que devem ser isolados, agrupados, tornados pertinentes, inter-relacionados, organizados em conjuntos" (FOUCAULT, 2008 [1969], p. 8), é a tarefa da arqueologia na história nova. Essa transformação consiste em desvencilhar o monumento da função de memória coletiva que lhe foi atribuída, a qual tende a fazê-lo falar "mais do que diz", tornando-o um documento. O fazer arqueológico na história nova é, sobretudo, um ato de desconfiança com relação ao que está dado, "documentalizado".

Essa dúvida também é mobilizada pela análise arqueológica do discurso quando questiona as noções do contínuo, localiza suas fragilidades e preconiza o olhar direcionado aos enunciados em dispersão. Certamente os procedimentos realizados a partir dessas unidades dispersas não são arbitrários, mas também resultantes de escolhas. A diferença é que são "decisões controladas". Em outras palavras, a partir do momento que se torna "operação deliberada do historiador" na história nova, a descontinuidade se apresenta também na metodologia do arqueólogo do discurso como fator de escolhas mais conscientes, de modo a tornar assinaláveis diversas relações que ficariam "invisíveis" entre os enunciados no que dependesse de análises estritamente linguísticas (atomísticas) de uma história contínua.

Contudo, admitimos que uma objeção poderia ser colocada à analogia apresentada: como falar em um discurso-monumento, se o monumento é analisado intrinsecamente na história nova, e a unidade básica da análise discursiva que abordamos - o enunciado - é tal que "nem a língua nem o sentido" podem esgotar? 0 que seria intrínseco ao enunciado senão o próprio sistema linguístico que lhe engendra? Tentaremos responder a estas questões a seguir. 


\section{A análise intrínseca do discurso-monumento}

Para responder se a análise delineada por Foucault é intrínseca ao discurso-monumento, vamos abordar sumariamente dois conceitos fundamentais na teoria, o de formação discursiva e o de função enunciativa. Tais noções, que dão substância respectivamente ao discurso e ao enunciado, ilustram a compreensão singular de Foucault acerca desses termos já conhecidos na metalinguagem linguística, bem como nos encaminham para a conclusão de que a análise discursiva é intrínseca, contanto que se compreenda as condições específicas a partir das quais se pode dizer isso.

Colocando em ação o plano de tratar os discursos como enunciados em dispersão, Foucault descobre não existir um elemento que dê sustentação aos discursos das ciências humanas. Seus estudos demonstram que nestas há sempre alguma forma de inconsistência ou heterogeneidade constituinte, como a concomitância de objetos, de formas de enunciação, de conceitos e de estratégias diversos.

Diante da impossibilidade de se sublinhar prontamente, nesses discursos, uma unidade, a análise do discurso foucaultiana procura mapear os sistemas de dispersão de objetos, modalidades enunciativas, conceitos e escolhas teóricas que neles figuram. Nessa perspectiva, a unidade dos discursos residiria nas regularidades que funcionam como regra e autorizam o jogo de dispersão desses elementos constitutivos.

Para que essas regularidades sejam encontradas, o filósofo oferece quatro conjuntos de regras de formação ${ }^{11}$, entendidas como condições de possibilidade para que os objetos, as formas enunciativas, os conceitos e as teorias figurem nos discursos. A partir da apreensão das maneiras através das quais essas condições de possibilidade se relacionam, são encontradas as regulari-

\footnotetext{
11 Embora seja tentador abordar mais pormenorizadamente tais instâncias, uma vez que a descrição destas organizada por Foucault clarifica em muito as discussões aqui transpostas, não o faremos por conta do espaço de que dispomos em um artigo. Portanto, vale conferi-las na segunda unidade da Arqueologia do Saber.
} 
A monumentalização do discurso na arqueologia do saber, de Michel Foucault Ana Carolina Neves Dias • Ana Paula El-Jaick

dades que organizam dispersão desses elementos em dado discurso. De acordo com Foucault,

[n]o caso em que se puder descrever, entre um certo número de enunciados, semelhante sistema de dispersão, e no caso em que entre os objetos, os tipos de enunciação, os conceitos, as escolhas temáticas, se puder definir uma regularidade (uma ordem, correlações, posições e funcionamentos, transformações), diremos, por convenção, que se trata de uma formação discursiva (FOUCAULT, 2008 [1969], p. 43).

Deste modo, na análise discursiva contam não apenas as regularidades que formam cada um desses domínios do discurso, mas estes devem ser relacionados entre si. As formas de enunciação, por exemplo, influem diretamente no jogo de conceitos presente em um discurso. Em contraste com as concepções que tomam o sujeito como a origem dos discursos, para a arqueologia, estes são "práticas que formam sistematicamente os objetos [e também as modalidades enunciativas, os conceitos e as teorias] de que falam" (FOUCAULT, 2008 [1969], p. 55). Isto significa que o processo de constituição de um discurso não lhe é externo, mas inerente à prática discursiva. Um exemplo que ilustra essa ideia é a maneira através da qual a teoria em questão concebe a formação dos conceitos: em um "nível pré-conceitual". Esse nível não diz respeito à elaboração mental do conceito por uma subjetividade psicológica, mas à própria organização do campo enunciativo. Para compreender o jogo dos conceitos, arqueologicamente falando, é necessário considerar, por exemplo, como determinado enunciado é compartilhado com outras formações discursivas, a quais procedimentos de intervenção os enunciados são submetidos, que intenções subjazem a retomada de enunciados já ditos, esquemas retóricos, dentre outros aspectos.

Por outro lado, se as regularidades discursivas não dizem respeito à consciência, tampouco o discurso como texto constrói suas regras por si. Principalmente no caso dos conceitos, parece ser 
A monumentalização do discurso na arqueologia do saber, de Michel Foucault Ana Carolina Neves Dias • Ana Paula El-Jaick

fácil nos inclinarmos a uma visão imanentista do texto: uma vez que o campo enunciativo deve ser considerado, poderíamos, inadvertidamente, entender sua estrutura como o abrigo das regras. Entretanto, como Foucault esclarece, os sistemas de formação não constituem "textos (ou as falas) tais como se apresentam com seu vocabulário, sintaxe, estrutura lógica ou organização retórica" (FOUCAULT, 2008 [1969], p. 84). Em um jogo de palavras com premissas chomskyanas, o filósofo francês esclarece que entre uma unidade profunda - que remete à mente do falante - e uma multiplicidade superficial - que remete ao texto em si - deve-se permanecer na "dimensão do discurso".

Assim, entrevemos a ideia de que o discurso é uma prática irredutível tanto a análises puramente formais quanto a análises psicológicas. Essa prática consiste em regras "anônimas, históricas, sempre determinadas no tempo e no espaço, que definiram, em uma dada época e para uma determinada área social, econômica, geográfica ou linguística, as condições de exercício da função enunciativa" (FOUCAULT, 2008 [1969], p. 133). A definição de prática discursiva que transpomos também não deixa de suscitar possíveis equívocos: se a regra da dispersão não está na consciência dos sujeitos, nem na superfície textual, uma alternativa seria associar as regularidades discursivas a contingências históricas, numa relação de causalidade. Mas logo Foucault adverte que a arqueologia, ao levar em conta aspectos históricos, intenciona

mostrar como a autonomia do discurso e sua especificidade não Ihe dão, por isso, um status de pura idealidade e de total independência histórica; o que ela [a análise discursiva] quer revelar é o nível singular em que a história pode dar lugar a tipos definidos de discurso que têm, eles próprios, seu tipo de historicidade e que estão relacionados com todo um conjunto de historicidades diversas. (FOUCAULT, 2008 [1969], p. 185-186).

A partir desse fragmento, compreendemos que reduzir as relações entre os acontecimentos históricos e o campo enunciativo 
A monumentalização do discurso na arqueologia do saber, de Michel Foucault Ana Carolina Neves Dias • Ana Paula El-Jaick

a laços causais seria correr o risco de retornar às ideias que sustentam a continuidade, as quais foram suspensas justamente pelo ponto de vista antropocêntrico sobre o mundo que ajudam a sustentar. Mais precisamente, ao considerar os fatores históricos, a arqueologia deseja mostrar que os discursos não são produzidos em uma espécie de vácuo, mas ocorrem efetivamente no tempo e no espaço. Ademais, considerar as condições de possibilidade de determinado discurso situadas na história (descontínua) permite estabelecer relações menos diretas daquelas já dadas, como as de influência ou de "espírito de época". Não se trata de atribuir a causa ou a modificação de determinado discurso a fatos históricos, mas de articulá-los às condições de existência dos objetos, das modalidades enunciativas, dos conceitos e das teorias a partir das quais se encontram as regularidades discursivas.

Após apresentar a noção de formação discursiva, em lugar de tratar o discurso em suas acepções mais convencionais, o professor francês desarma seu leitor ao definir o enunciado por meio da noção de função enunciativa. Se o enunciado possui uma natureza que "nem a língua nem o sentido" podem esgotar é porque ele está além de regras formais ou estruturais: é uma função que cruza domínios virtuais. Conforme o filósofo, o referencial do enunciado "forma o lugar, a condição, o campo de emergência, a instância de diferenciação dos indivíduos ou dos objetos, dos estados de coisas e das relações que são postas em jogo pelo próprio enunciado" (FOUCAULT, 2008 [1969], p. 103, grifo nosso) ${ }^{12}$. Assim como no nível do discurso as regras são intrínsecas à prática discursiva, também no nível do enunciado as regras são construídas em seu limite de existência: o referencial do enunciado é um conjunto de domínios de possibilidades relacionados pela função enunciativa.

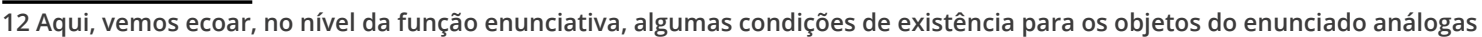
àquelas necessárias aos objetos do discurso no âmbito das regras de formação discursiva: um campo de emergência e uma instância de diferenciação. Assim, vê-se uma simetria entre a dimensão discursiva e a dimensão enunciativa, no cerne da teoria foucaultiana: bem como na formação discursiva é um conjunto de relações que estabelece o regime dos objetos, também no nível do enunciado é um conjunto de relações que define sobre o que se diz. Há outros pontos fundamentais na definição de função enunciativa que também remetem a outros agrupamentos de regras de formação para os domínios da formação discursiva. Contudo, tratar estes pontos aqui implicaria estender este artigo em demasia. Como nosso objetivo é demonstrar em que medida o âmbito discursivo é abordado intrinsecamente por Foucault, acreditamos que é suficiente situar o referencial do enunciado.
} 
A partir disso, esboçamos algumas conclusões: como na formação discursiva é um conjunto de relações que estabelece o regime dos objetos, também no nível do enunciado é um conjunto de relações que define sobre o que se diz. Ademais, assim como no nível do discurso as regras não são externas, mas intrínsecas à prática discursiva, também no nível do enunciado as regras são construídas em seu limite de existência.

Destarte, podemos retomar a pergunta que motiva esta seção, afirmando que a análise do discurso foucaultiana é intrínseca ao discurso, se compreendemos que o intrínseco não estabelece aqui uma relação de sinonímia com uma essência ou interioridade. Na Arqueologia do Saber, o discurso é concebido como "conjunto de enunciados que se apoia em um mesmo sistema de formação" (FOUCAULT, 2008 [1969], p. 122), sendo que este sistema envolve diferentes domínios e a sinalização de relações entre instâncias discursivas e não-discursivas. Logo, por conta de a própria definição de discurso abrir para si um emaranhado de relações, o que Ihe é intrínseco está mais perto de uma analogia com pontos de intersecção em um mapa cheio de cruzamentos, extenso e ramificado, do que de um átomo indivisível. Só assim entendemos como o feixe de relações que constitui a regularidade discursiva, a regra que estabelece o regime enunciativo, é intrínseca.

Com esta argumentação, fechamos o círculo que nos propusemos a delinear neste trabalho, confirmando a tese segundo a qual é possível estabelecer um paralelo entre a função assumida pela arqueologia na história nova e a sua função no âmbito da análise discursiva concebida por Foucault. A primeira razão é a de que a transformação do documento em monumento relaciona-se diretamente com a transformação do discurso em um campo de enunciados em dispersão: ambas possibilitam compreender o dado como uma positividade, desviando-se de relações imprecisas que tanto na história propriamente dita quanto na história do pensamento servem a um humanismo reducionista.

A segunda razão é a de que, como acabamos de ver, em decorrência de o discurso não existir sem uma prática histórica e so- 
A monumentalização do discurso na arqueologia do saber, de Michel Foucault Ana Carolina Neves Dias • Ana Paula El-Jaick

cialmente situada, sua intrinsecidade é indissociável de aspectos extralinguísticos. Assim se justifica a esquiva foucaultiana de definições essencialistas para o discurso e o enunciado e o recurso a conjuntos de regras de formação para a formação discursiva e a conjuntos de condições de exercício para a função enunciativa. Finalmente, é dessa forma que podemos defender que, enquanto a arqueologia, na história nova, se dedica à "descrição intrínseca do monumento", a arqueologia, na análise do discurso, se dedica à descrição intrínseca de um discurso-monumento.

\section{Considerações finais}

Neste trabalho, nos dedicamos a um texto importante para os estudos da linguagem, a Arqueologia do Saber, em que Foucault reforça e retifica, a um só tempo hesitante e contundente, o tom de sua teoria. Apresentamos a popularidade crescente do gerativismo e a efervescência de disciplinas surgindo nos meados do século anterior, bem como as correntes na filosofia da linguagem que marcaram sua primeira metade como parte da atmosfera que envolve seu lançamento. Tentou-se demonstrar ainda porque e com que finalidade o professor do Collège de France defende a descontinuidade neste escrito quinquagenário: para se opor às formas de história positivista que apagam a multiplicidade de acontecimentos, moldando narrativas históricas que privilegiam a consciência humana.

Em seguida, retomamos o passo metodológico inicial da análise discursiva - ver os discursos como enunciados em dispersão, a fim de compreendê-los em sua positividade de acontecimentos, explicando que a principal vantagem disso é encontrar novas relações no campo enunciativo. Deste modo, pudemos associar essa atitude fundamental na análise foucaultiana do discurso à transformação do documento em monumento, operada pela arqueologia no âmbito da história propriamente dita; afinal, colocar o "dado" à prova é um interesse comum às duas arqueologias. 
A monumentalização do discurso na arqueologia do saber, de Michel Foucault Ana Carolina Neves Dias • Ana Paula El-Jaick

Contudo, ao apresentarmos - ainda que sumariamente - as noções de formação discursiva e de função enunciativa, constituintes do discurso e do enunciado, respectivamente, é que consolidamos a concepção de um discurso-monumento, já que, a exemplo da arqueologia na história nova, intrínseca ao monumento, a análise foucaultiana é intrínseca ao discurso. Sintetizamos o caminho: porque a unidade do discurso reside em seu sistema de formação - que, por sua vez, consiste em um conjunto de relações empregadas de modo constante -, ao oferecer-nos ferramentas conceituais para que estas sejam encontradas, a análise arqueológica propõe-se intrínseca a este. Assim, preserva-se a positividade própria de tudo o que é dito, ou escrito, evitando o apagamento da materialidade discursiva em busca de uma causa, de uma regra anterior à prática discursiva.

Por caracterizar-se como uma teoria a qual vê a regra como inerente ao próprio funcionamento da linguagem, e não como uma existência anterior ao uso, a análise arqueológica avizinha-se de uma visão pragmática de linguagem, embora mantenha consideráveis distanciamentos em relação a esta - o que pode vir a ser tema de outros estudos, já que não dispomos de mais espaço neste artigo. Muitas interrogações permanecem, como de que forma a ideia de monumento, considerada em recortes maiores do que $o$ deste livro, poderia ser pensada nos estudos linguísticos. É este último questionamento que procuraremos desenvolver na próxima etapa desta pesquisa, na pós-graduação.

\section{Referências}

AUROUX, Sylvain. O que é a filosofia da linguagem. In: AUROUX, Sylvain. A filosofia da linguagem. Campinas: Editora da Unicamp, 1998. p. 11-21.

BATISTA, Ronaldo de Oliveira. Introdução à Historiografia da Linguística. São Paulo: Cortez Editora, 2013. 
A monumentalização do discurso na arqueologia do saber, de Michel Foucault Ana Carolina Neves Dias • Ana Paula El-Jaick

CHOMSKY, Noam. Syntactic Structures. The Hague, Paris: Mouton, 1957.

DELEUZE, Gilles. Foucault. São Paulo: Brasiliense, 2013 [1987].

Tradução de: Claudia Sant'Anna Martins.

DOSSE, François. História do estruturalismo vol. 1: o campo do signo 1945-1966. São Paulo: Editora Unesp, 2018[1991]. Tradução de: Álvaro Cabral.

DREYFUS, Hubert; RABINOW, Paul. Michel Foucault: uma trajetória filosófica para além do estruturalismo e da hermenêutica. Rio de Janeiro: Forense Universitária, 1995.

FOUCAULT, Michel. A Arqueologia do Saber. 7. ed. Rio de Janeiro: Forense Universitária, 2008[1969]. Tradução de: Luiz Felipe Baeta Neves.

FOUCAULT, Michel. A Ordem do Discurso. 3. ed. São Paulo: Loyola, 1996 [1971].

KOERNER, E.F.K. Professing Linguistic Historiography. Amsterdam/ Philadelphia: John Benjamins, 1995.

LYOTARD, Jean-François. A condição pós-moderna. 2. ed. Lisboa: Gradiva, 1989.

MARCONDES, Danilo. Apresentação. In: AUSTIN, John Langshaw. Quando dizer é fazer. Porto Alegre: Artes Médicas, 1990. p. 7-17.

MARCONDES, Danilo. Em defesa de uma concepção pragmática de linguagem. Gragoatá, Niterói, v. 18, n. 1, p. 11-29, 30 mar. 2005. Disponível em: https://periodicos.uff.br/gragoata/article/ view/33273/19260. Acesso em: 20 jul. 2020.

MACHADO, Roberto. Primeira Parte: a história epistemológica de Georges Canguilhem. In: MACHADO, Roberto. Foucault, a ciência e o saber. 3 ed. Rio de Janeiro: Jorge Zahar Ed., 2006. p. 14-47.

MARCUSCHI, Luiz Antônio. Breve excurso sobre a linguística no século XX. In: MARCUSCHI, Luiz Antônio. Produção textual, análise de gêneros e compreensão. São Paulo: Parábola, 2008, p.25-46. 
A monumentalização do discurso na arqueologia do saber, de Michel Foucault Ana Carolina Neves Dias • Ana Paula El-Jaick

BARBOSA, Pedro Luis Navarro. O acontecimento discursivo e a construção da identidade na História. In: SARGENTINI, Vanice; BARBOSA, Pedro Luis Navarro. Foucault e os domínios da linguagem: discurso, poder, subjetividade. São Carlos: Claraluz, 2004, p.97-130.

SWIGGERS, Pierre. História, Historiografia da Linguística: status, modelos e classificações. Eutomia, Recife, v. 1, n. 6, p. 1-17, dez. 2010. Disponível em: https://periodicos.ufpe.br/revistas/EUTOMIA/article/ download/1702/1289. Acesso em: 24 abr. 2020.

SWIGGERS, Pierre. A historiografia da linguística: objeto, objetivos, organização. Confluência: Revista do Instituto de Língua Portuguesa, Rio de Janeiro, v. 4, n. 44, p. 39-59, 2013. Disponível em: http://llp.bibliopolis. info/confluencia/pdf/1171.pdf. Acesso em: 26 jul. 2020.

VEIGA-NETO, Alfredo. Michel Foucault e a educação. 2. ed. Belo Horizonte: Autêntica, 2006.

WEEDWOOD, B. História Concisa da Linguística. Tradução: Marcos Bagno. São Paulo: Parábola, 2002. 